\title{
Septum Primum
}

National Cancer Institute

\section{Source}

National Cancer Institute. Septum Primum. NCI Thesaurus. Code C34294.

A wall of cardiac tissue that forms the initial, incomplete separation of the right and left atria during early heart development in the embryo. 